THE KURUME MEDICAL JOURNAL Vol. 16, No. 4, 1969.

\title{
A STUDY ON THE CENTRAL RETINAL VEIN OCCLUSION REPORT 3. FLUORESCEIN ANGIOGRAPHIC FINDINGS IN SITE OF VENOUS OBSTRUCTION
}

\author{
HISAHARU YOSHIOKA AND TAKASHI SUGITA \\ Department of Ophthalmology, Kurume University School \\ of Medicine, Kurume, Japan
}

(Received for publication September 22, 1969)

The importance of the arteriovenous crossing as the site of tributary occlusion has been confirmed fluorescein angiographically by many authors ${ }^{1 / 3)}$ 13). However, the grade and location of venous obstruction in an arteriovenous crossing have still been controversial.

In previous report ${ }^{10}$ ) we have informed an interesting finding that two types of venous obstruction were shown at an arteriovenous crossing, and we have briefly discussed its significance.

The purpose of this paper is to more clarified the findings of an arteriovenous crossing by fluorescein angiography.

\section{MATERIALS AND METHOD}

Twenty two cases among the patients with tributary occlusion that the site of obstruction was confirmed by fluorescein angiography were selected except for the patients that the site of venous obstruction at an arteriovenous crossing was obscure by the retinal hemorrhages and edema, and was not confirmed because out of the field of photography. And also the site of venous obstruction in these same patients were often followed up in the period of three months to two years.

The method of fluorescein angiography was same as previously described ${ }^{10}$.

\section{RESULTS}

The angiographic findings of twenty two patients with tributary occlusion are shown in Table 1 and 2.

A. The site of venous obstruction

In twenty two cases it was confirmed that the site of venous obstruction was all at an arteriovenous crossing. The site of these crossing was either in the first crossing between main retinal artery and main retinal vein or in the 
TABLE 1

Grade and location of venous obstruction at an arteriovenous crossing

\begin{tabular}{|c|c|c|c|c|c|c|c|}
\hline \multirow[b]{2}{*}{$\begin{array}{c}\text { Case } \\
\text { No. }\end{array}$} & \multirow[b]{2}{*}{$\begin{array}{c}\text { Period after } \\
\text { onset }\end{array}$} & \multicolumn{2}{|c|}{$\begin{array}{l}\text { Grade of venous } \\
\text { obstruction }\end{array}$} & \multicolumn{4}{|c|}{ Location of venous obstruction } \\
\hline & & Complete & Partial & $\begin{array}{l}\text { Proximal } \\
\text { side }\end{array}$ & $\begin{array}{l}\text { Peripheral } \\
\text { side }\end{array}$ & $\begin{array}{l}\text { Both proxi- } \\
\text { mal and } \\
\text { peripheral } \\
\text { side }\end{array}$ & $\begin{array}{l}\text { Just cross- } \\
\text { ing portion }\end{array}$ \\
\hline 1. & 7 days & + & & + & & & \\
\hline 2. & 10 days & & + & & + & 1 & \\
\hline 3. & 10 days & & + & & & & + \\
\hline 4. & One month & & + & + & & & \\
\hline 5. & One month & + & & & + & 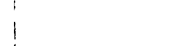 & \\
\hline 6. & One month & & + & + & & $!$ & \\
\hline 7. & $\begin{array}{l}\text { Two and half } \\
\text { Month }\end{array}$ & & + & & + & & \\
\hline 8. & Three months & + & & & + & & \\
\hline 9. & Six months & & + & & + & 1 & \\
\hline 10. & Seven months & + & & & + & $!$ & \\
\hline 11. & $\begin{array}{l}\text { One year and } \\
\text { three months }\end{array}$ & & + & + & & i & \\
\hline 12. & $\begin{array}{l}\text { One year and } \\
\text { five months }\end{array}$ & & + & & + & & \\
\hline 13. & $\begin{array}{l}\text { One year and } \\
\text { nine months }\end{array}$ & + & & & + & & \\
\hline 14. & Two years & + & & & + & & \\
\hline 15. & Two years & + & & & & + & \\
\hline 16. & $\begin{array}{l}\text { Two years and } \\
\text { seven months }\end{array}$ & + & & & + & & \\
\hline 17. & Three years & + & & & + & & \\
\hline 18. & $\begin{array}{l}\text { Three years and } \\
\text { three months }\end{array}$ & & + & & & + & \\
\hline 19. & $\begin{array}{l}\text { Three years and } \\
\text { seven months }\end{array}$ & + & & & + & & \\
\hline 20. & $\begin{array}{l}\text { Four years and } \\
\text { one month }\end{array}$ & + & & & + & & \\
\hline 21. & $\begin{array}{l}\text { Five years and } \\
\text { three months }\end{array}$ & & + & + & & t & \\
\hline 22. & Six years & + & & & & + & \\
\hline
\end{tabular}

crossing between main retinal artery and the first branch of main retinal vein from optic disc. At the crossing the retinal artery crossed over the retinal vein in most cases and retinal vein crossed rarely over the retinal artery.

\section{B. The grade of venous obstruction}

In twenty two cases, twelve cases were complete and ten cases were partial. As shown in Table 1, we saw a complete obstruction in only one fresh case (Case 1) that is seven days after onset but we had partial obstruction in two old cases (Case 18 and 21) that are even two years or more after onset. 
TABLE 2

Angiographic findings in retinal artery

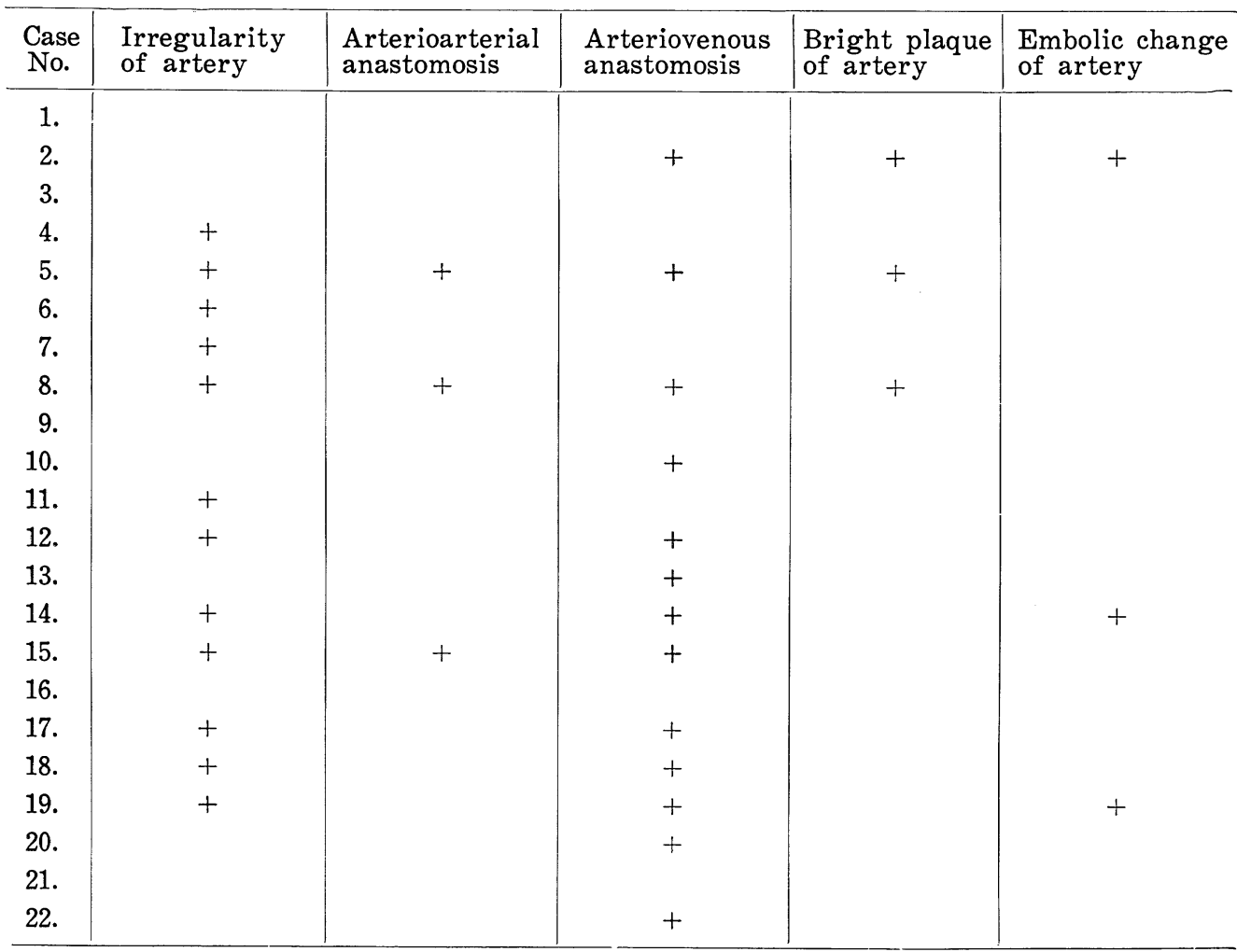

In follow up examination of all cases, there was a case (Case 6) (Fig. 1 and 2) that partial obstruction became to open but there was no case that partial obstruction altered to complete obstruction or complete obstruction altered to partial obstruction.

C. The location of venous obstruction at an arteriovenous crossing

There were several different types in location of venous obstruction at an arteriovenous crossing. In partial obstruction, there were three types; proximal side type (four cases) (Fig. 3), peripheral side type (four cases) (Fig. 4), both proximal and peripheral side type (one case), and just crossing portion type (one case) (Fig. 1, 2.). In complete obstruction, there were three types; peripheral side type (nine cases) (Fig. 5, 6), or rarely, both proximal and peripheral side type (two cases) (Fig. 7,8) and proximal side type (one case) (Fig.9). 


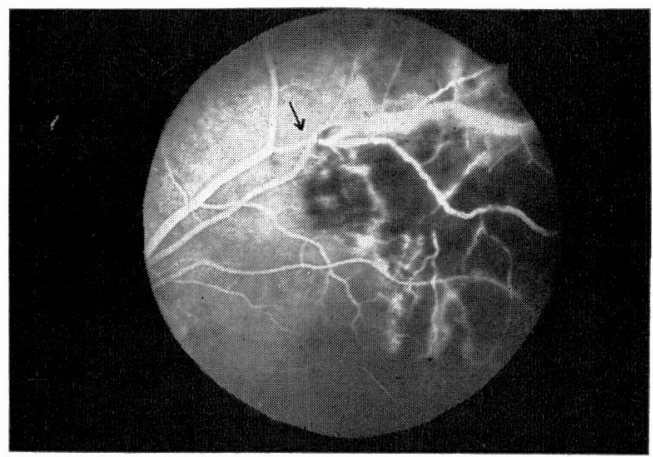

Fig. 1 (Case 3, ten days after onset) shows the partial obstruction in just portion at an arteriovenous crossing. The site of this crossing is in between main superior temporal artery and the first branch of main superior temporal vein. In this case vein is on the artery. Forty one seconds after injec tion.

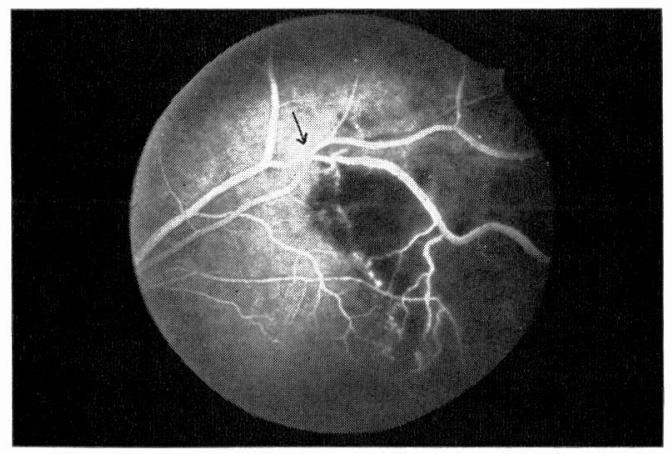

Fig. 2 (Same as Case 3) shows enlargement of partial obstruction. Twenty nine seconds after injection.

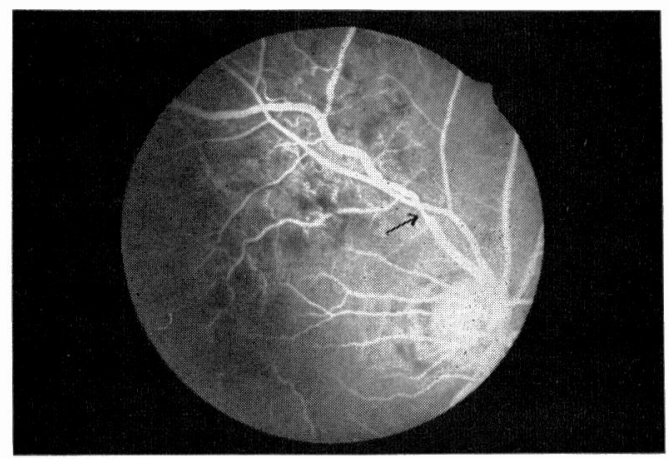

Fig. 3 (Case 4, one month after onset) shows the partial obstruction in proximal side at an arteriovenous crossing. The site of this crossing is in the first crossing between main superior temporal artery and main superior temporal vein. Twenty one seconds after injection. 


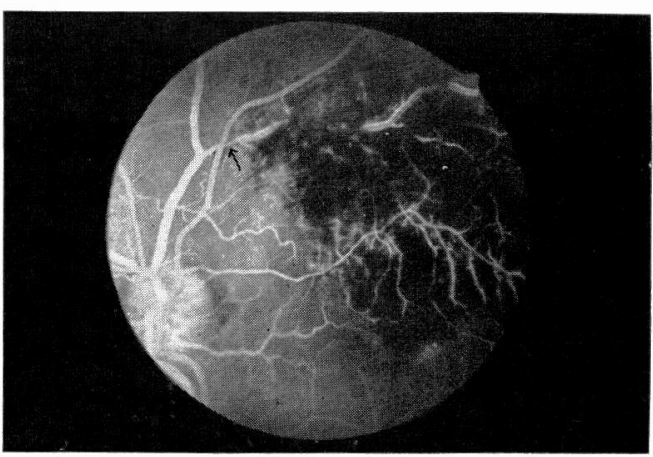

Fig. 4 (Case 7, two and half months after onset) shows partial obstruction in peripheral side at an arteriovenous crossing. The site of this crossing is in between main superior temporal artery and the first branch of main superior temporal vein. Thirty one seconds after injection.

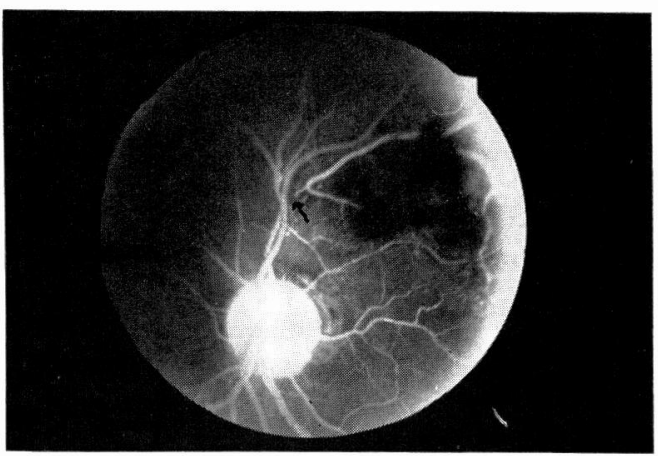

Fig. 5 (Case 5, one month after onset) shows complete obstruction in peripheral side at an arteriovenous crossing. In this case there is a bright plaque in artery of just proximal portion of this crossing. Thirty nine seconds after injection.

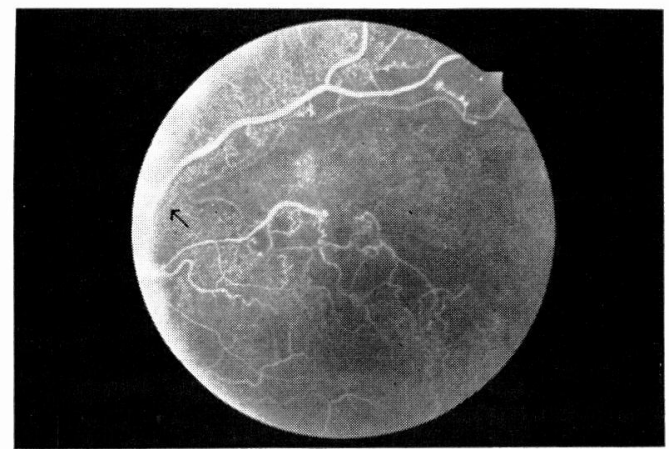

Fig. 6 (Case 19, three years and seven months after onset) shows complete obstruction in peripheral side at an arteriovenous crossing. In this case there is also embolic change. Twenty one seconds after injection. 


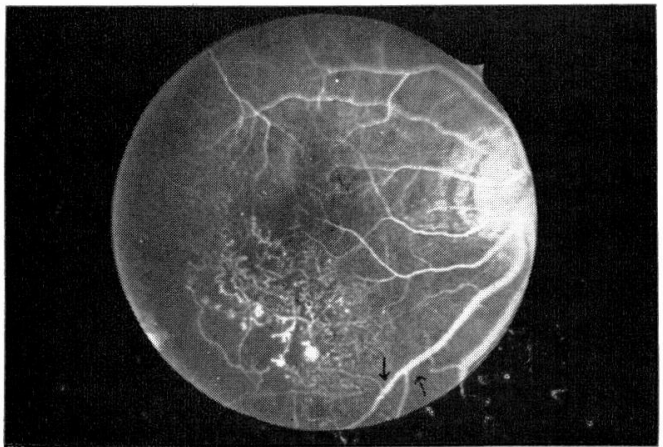

Fig. 7 (Case 15, two years after onset) shows complete obstruction in both proximal and peripheral side at an arteriovenous crossing.

Twenty three seconds after injection.

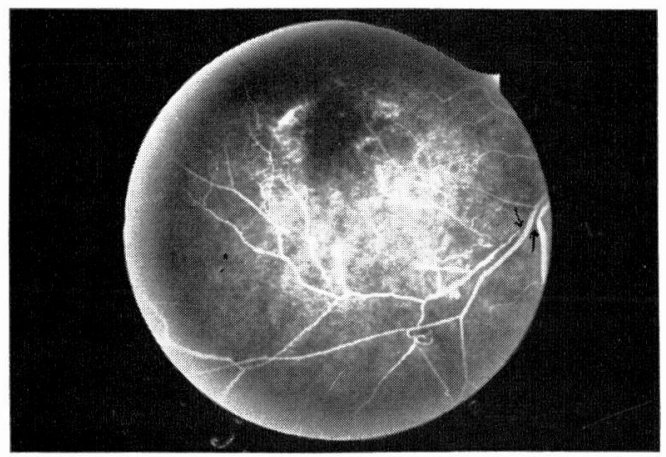

Fig. 8 (Case 22, six years after onset) shows complete obstruction in both proximal and peripheral side at an arteriovenous crossing. The site of Case 15 and 22 are in between main inferior temporal artery and the first branch of main inferior temporal vein.

Sixty three seconds after injection.

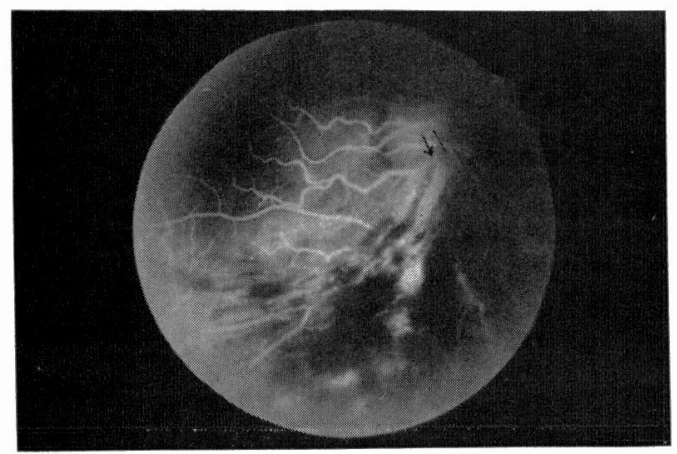

Fig. 9 (Case 1, seven days after onset) shows complete obstruction in proximal side at an arteriovenous crossing on the optic disc. Sixty eight seconds after injection. 


\section{COMMENT}

It has been confirmed by many authors ${ }^{1 / 3)}{ }^{313}$ ) that the site of obstruction is recognized in the arteriovenous crossing. But the location of this crossing was not fully demonstrated in tributary occlusion. This evidence was very good demonstrated by fluorescein angiography and this location was either in the first crossing between main retinal artery and main retinal vein or between main retinal artery and the first branch of main retinal vein. Therefore, it was also confirmed that predisposing site in this disease existed in the site of arteriovenous crossing. Because this may probably be explained from the fact that there is the most marked difference in blood pressure between intraocular retinal artery and retinal vein in this site.

The grade of venous obstruction at an arteriovenous crossing is still one of the controversial aspects. Several authors ${ }^{3 / 8) 13)}$ have been described the opinion that complete obstruction of vein at an arteriovenous crossing in recent tributary occlusion has never been observed by fluorescein angiography. On the contrary, it has been noted by Gass ${ }^{1)}$ that the obstruction may be complete or partial.

The facts that complete obstruction was observed in patient seven or ten days after onset, partial obstruction was observed in patient one year or more years after onset, and there was no case by follow up examination that partial obstruction changed to complete obstruction or complete obstruction changed to partial obstruction strongly suggest that the grade of venous obstruction may be determined at onset of this disease. Moreover, the fact that various degree of fundus findings were ophthalmoscopically observed soon after onset supports this assumption.

The location of venous obstruction at an arteriovenous crossing shows the very interesting findings. The location of venous obstruction may consists of four types; proximal side type, peripheral side type, both proximal and peripheral side type, and just crossing portion type. It should be emphasized that there is apparent difference between proximal side type and peripheral side type. In peripheral side type, there are many findings of arterial insufficiency demonstrating retinal artery occlusion, bright plaque in arteriole, marked irregularity or narrowing of the artery, and arterioarterial or arteriovenous anastomosis. On the contrary, the findings of arterial insufficiency are minimal in proximal side type.

Considering of the Hayreh's experimental results ${ }^{2)}$, these findings suggest that two factors of arterial insufficiency and compression of artery at an arteriovenous crossing may be necessary in development of tributary occlusion. Fluorescein angiography demonstrates the site, grade, location, and availability of collateral vessel at an arteriovenous crossing. Therefore, fluorescein angiography may be very helpful in deciding the prognosis and effect of therapy. For deciding the effect of therapy of this disease, especially the period from 
onset, grade and location of venous obstruction at an arteriovenous crossing must be considered.

\section{CONCLUSION}

1. The site of venous obstruction in tributary occlusion is always in arteriovenous crossing and predisposing site of these crossing is either in the first crossing between main retinal artery and main retinal vein or in the crossing between main retinal artery and the first branch of main retinal vein.

2. The venous obstruction may be complete or partial. The location of venous obstruction in arteriovenous crossing may be in proximal and peripheral side, or less commonly, in just crossing portion or rarely in both proximal and peripheral side.

3. There is a case that partial obstruction becomes to enlarge but there is no case that partial obstruction alter to complete obstruction or complete obstruction alter to partial obstruction.

4. The participation of arterial insufficiency in case with venous obstruction in peripheral side type is much more stronger than those with venous obstruction in proximal side type.

From above these findings, angiographic findings in site of above mentioned arteriovenous crossing is very useful to deciding the grade and location of venous obstruction, availability of collateral vessel, and prognosis of this disease.

\section{ACKNOWLEDGEMENT}

We wish to thank Dr. Prof. Y. Masuda of the Department of Ophthalmology for his revision and his kind advices.

\section{REFERENCES}

1) GAss, J.D. M. : A fluorescein angiographic study of macular dysfunction secondary to retinal vascular disease II. Retinal vein obstruction. Arch. of Ophthal. 80:550, 1968.

2) Hayreh, S. S. : Occlusion of the central retinal vessels. Brit. J. Ophthal. 49:626, 1965.

3 ) JÜtте, A. und LemKe, L. : Intravitalfärbung am Augenhintergrund mit Fluoreszein-Natrium Ferdinand. Enke Verlag, Stuttgart, 1968.

4) KIDo, A.: A study on retinal haemorrhage by means of fluorescein fundus photography. Jap. J. Clin. Ophthal. $22: 183,1968$.

5) Matsui, M., KoH, K. and TAshiro, T.: Studies on the fluorescence fundus-photo graphy. Part II. Clinical significances of the serial fluorescence fundus-photography in some retinal vascular lesions. Acta Soc. Ophth. Jap. $70: 613,1966$.

6 ) OJsterhuis, J. A. : Fluorescein fundus photography in retinal vein occlusion. Henkes, H. E. Perspectives in Ophthalmology Excerpta Medica Foundation, 1968, p. 29. 
7) RAitta, C.: Fluorescein angiography after central vein occlusion. Acta Ophthal. $46: 207,1968$.

8) SEITZ, R.: Klinik und Pathologie der Netzhautgefässe Ferdinand. Enke Verlag, Stuttgart, 1968.

9) Shikano, S. and Shimizu, K.: Atlas of fluorescence fundus angiography. Igaku Shoin, Tokyo, 1968.

10) Sugita, T. and Yoshioka, H.: A study on the obstruction of the central retinal vein. Report II. Fluorescein photographic findings of the fundus. Folia Ophthal. Jap. $19: 767,1968$.

11) TANI, M. : Fluorescein studies on occlusion of the retinal vein. Jap. J. Clin. Ophthal. $21: 1365,1967$.

12) Wessing, A.: Fluoreszenzangiographie der Retina, Lehrbuch und Atlas. George Thieme Verlag, Stuttgart, 1968.

13) Zingirian, M. e Ciurlo, G. : L'angiografia a fluorescenza nelle trombosi della vena centrale retinica. Ref. Zbl. f. ges. Ophthal. $96: 539,1966$. 